\title{
Novel Insights into Chk1 Regulation by Phosphorylation
}

\author{
Hidemasa Goto ${ }^{1,2}$, Kousuke Kasahara ${ }^{1,3}$, and Masaki Inagaki ${ }^{1,2 *}$ \\ ${ }^{1}$ Division of Biochemistry, Aichi Cancer Center Research Institute, Nagoya, Aichi 464-8681, Japan, \\ ${ }^{2}$ Department of Cellular Oncology, Nagoya University Graduate School of Medicine, Nagoya, Aichi \\ 466-8550, Japan, ${ }^{3}$ Department of Oncology, Graduate School of Pharmaceutical Sciences, Nagoya City \\ University, Nagoya, Aichi, 467-8603, Japan
}

\begin{abstract}
Checkpoint kinase 1 (Chk1) is a conserved protein kinase central to the cell-cycle checkpoint during DNA damage response (DDR). Until recently, ATR, a protein kinase activated in response to DNA damage or stalled replication, has been considered as the sole regulator of Chk1. Recent progress, however, has led to the identification of additional protein kinases involved in Chk1 phosphorylation, affecting the subcellular localization and binding partners of Chk1. In fact, spatio-temporal regulation of Chk1 is of critical importance not only in the DDR but also in normal cell-cycle progression. In due course, many potent inhibitors targeted to Chk1 have been developed as anticancer agents and some of these inhibitors are currently in clinical trials. In this review, we summarize the current knowledge of Chk1 regulation by phosphorylation.
\end{abstract}

Key words: Chk1, cell-cycle checkpoint, phosphorylation

\section{Introduction}

DNA damage or stalled replication is sensed by cell-cycle checkpoints, which arrest the cell cycle to allow the time necessary to repair damaged DNA or to relieve the stalled replication fork (Ciccia and Elledge, 2010; Jackson and Bartek, 2009). These checkpoint signals are mediated by two evolutionally conserved protein kinases, ataxiatelangiectasia mutated (ATM) (Cremona and Behrens, 2014; Shiloh and Ziv, 2013)/ATM- and Rad3-related (ATR; Fig. 1) (Cimprich and Cortez, 2008; Flynn and Zou, 2011; Zeman and Cimprich, 2014). ATM and ATR phosphorylate and then activate checkpoint kinase 2 (Chk2) (Antoni et al., 2007) and Chk1(Lukas et al., 2003; Reinhardt and Yaffe, 2009; Zhang and Hunter, 2014), respectively (Fig. 1). The ATM-Chk2 pathway primarily reacts to DNA double strand

\footnotetext{
*To whom correspondence should be addressed: Masaki Inagaki, Division of Biochemistry, Aichi Cancer Center Research Institute, Nagoya, Aichi 464-8681, Japan.

Tel: +81-52-762-6111 (ext. 7020), Fax: +81-52-763-5233

E-mail: minagaki@aichi-cc.jp

Abbreviations: ATM, ataxia-telangiectasia mutated; ATR, ATM- and Rad3-related; $\beta$-TrCP, $\beta$-transducin repeated-containing protein; $\mathrm{CDK}$, cyclin-dependent kinase; Chk, Checkpoint kinase; DDR, DNA damage response, DSB, DNA double strand break; MAPK, mitogen-activated protein kinase; MK2, MAPK-activated protein (MAPKAP) kinase-2; NES nuclear export signal; NLS, nuclear localization signal; RSK, ribosomal S6 kinase; PKB, protein kinase B; ssDNA, single strand DNA; UV, ultraviolet.
}

break (DSB; Fig. 1). With regard to cell-cycle arrest, the transcription factor p53 is one of the most important substrates for ATM and Chk2 (Fig. 1) (Appella and Anderson, 2001; McGowan, 2002; Polager and Ginsberg, 2009; Riley et al., 2008). These phosphorylations block p53 degradation by E3 ligase MDM2 (Fig. 1) (Appella and Anderson, 2001; Polager and Ginsberg, 2009; Riley et al., 2008; Wade et al., 2013). The stabilized p53 induces p21, which binds and then inhibits cyclin-dependent kinases (CDKs; Fig. 1) (Polager and Ginsberg, 2009; Riley et al., 2008). Unlike ATM-Chk2, the ATR-Chk1 pathway detects a broader spectrum of DNA abnormalities (e.g. UV light, DNA replication inhibition, interstrand DNA crosslinking, or DSB end resection; Fig. 1). With regard to cell-cycle arrest, Cdc25A phosphatase is an essential target for Chk1 (Fig. 1) (Boutros et al., 2007; Goto et al., 2012; Neely and PiwnicaWorms, 2003). Chk1-induced phosphorylation triggers Cdc25A polyubiquitination and degradation (Fig. 1) (Boutros et al., 2007; Busino et al., 2004; Jin et al., 2003; Neely and Piwnica-Worms, 2003). Since Cdc25A is a critical phosphatase for CDK activation (Boutros et al., 2007; Goto et al., 2012), the activation of ATR-Chk1 pathway results in cell-cycle arrest (Fig. 1).

In cancer cells, the ATM-Chk2-p53 pathway is often impaired due to the mutations or deletions of ATM, CHEK2, and/or TP53 (Antoni et al., 2007; Cremona and Behrens, 2014; Goto et al., 2012; Riley et al., 2008; Shiloh and Ziv, 2013). These mutations are also identified as can- 


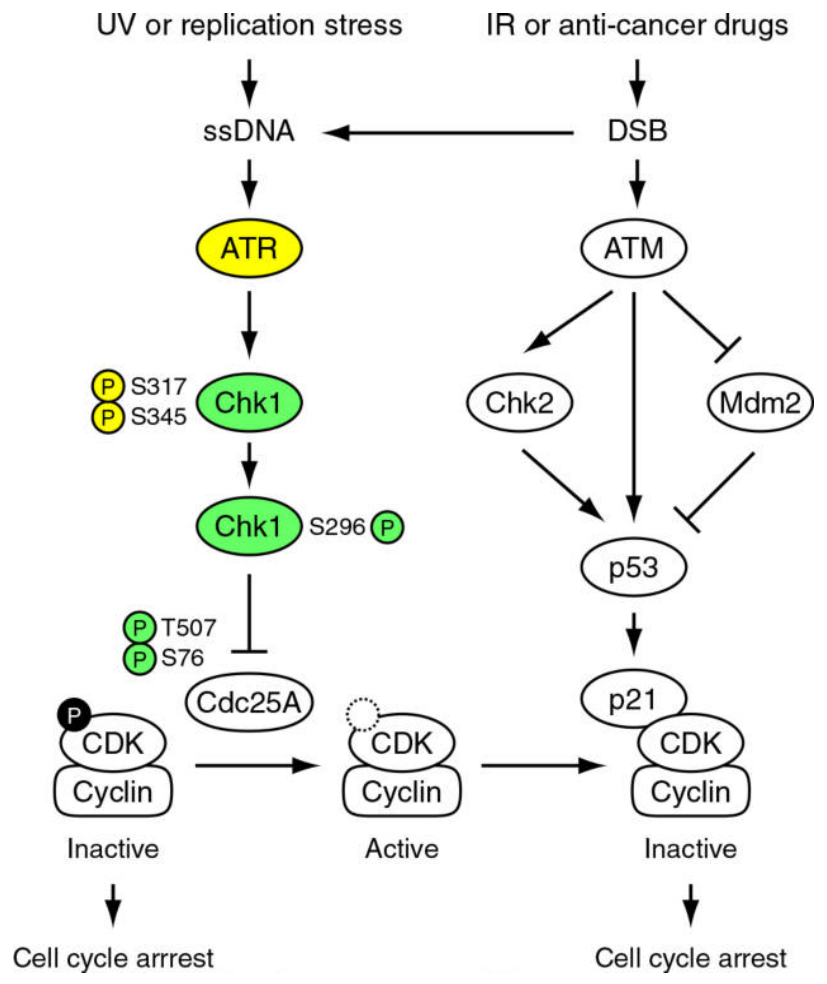

Fig. 1. A schema of DNA damage/replication checkpoint responses. The ATM-Chk2-p53 pathway is activated by DNA double strand breaks (DSBs), whereas the activation of ATR-Chk1-Cdc25A pathway is induced by single strand DNA (ssDNA) adjacent to double strand DNA. At the S or G2 phase of the cell cycle, DSBs are processed to ssDNA, which secondly activates the ATR-Chk1-Cdc25A pathway. The activation of these pathways ultimately suppresses cyclin-dependent kinases (CDKs).

cer driver mutations involved in tumor initiation and progression (Kandoth et al., 2013; Lawrence et al., 2014; Vandin et al., 2012). Due to this defect, cancer cells rely much more heavily on the ATR-Chk1-Cdc25A pathway for survival than normal cells (Goto et al., 2012; Zhang and Hunter, 2014). Chk1 inhibitors were originally developed and tested to sensitize tumors to existing cancer therapies, such as radiation therapy and chemotherapy with various DNA-damaging agents and/or anti-metabolites (Carrassa and Damia, 2011; Dai and Grant, 2010; Ma et al., 2011). Since Chk1 also regulates normal (unperturbed) cell-cycle progression (Goto et al., 2012; Zhang and Hunter, 2014), Chk1 inhibitors are also expected to kill cancer cells as single agents (Carrassa and Damia, 2011; Maugeri-Sacca et al., 2013; Thompson and Eastman, 2013). Due to the fact that the mechanism underlying Chk1 function in normal (unperturbed) cell-cycle progression remains poorly understood (Goto et al., 2012; Zhang and Hunter, 2014), little is known about the mechanisms by which Chk1 inhibitors preferentially kill cancer cells without inducing exogenous DNA damages.
Chk1 phosphorylation by ATR is essential for cell-cycle checkpoint (especially at the intra-S phase or at the G2/M transition) (Capasso et al., 2002; Niida et al., 2007; Wilsker et al., 2008) and conserved from yeast to mammals (Rhind and Russell, 2000). Recent studies have also revealed that Chk 1 is phosphorylated and regulated by various types of protein kinases other than ATR (Goto et al., 2012; Zhang and Hunter, 2014). In this review, we will summarize functional change of Chk1 by phosphorylation with a particular focus on human Chk1.

\section{Chk1 Phosphorylation by ATR}

ATR activation requires the generation of structures containing single strand DNA (ssDNA) adjacent to double strand DNA (dsDNA; Fig. 1) (Cimprich and Cortez, 2008; Flynn and Zou, 2011; Zeman and Cimprich, 2014). Such ssDNA is coated with replication protein A (RPA) complex and then attracts the complex of ATR and its regulatory protein ATR-interacting protein (ATRIP) (Cimprich and Cortez, 2008; Flynn and Zou, 2011; Zeman and Cimprich, 2014). The accumulation of ATR/ATRIP complex to damage sites results in initial (weak) activation of ATR (Cimprich and Cortez, 2008; Flynn and Zou, 2011; Zeman and Cimprich, 2014). The ssDNA-RPA structure also functions as a platform to recruit a number of checkpoint regulators including Rad17, Rad9-Hus1-Rad1 (9-1-1) complex, DNA topoisomerase II binding protein 1 (TopBP1), Timeless (TIM), TIM-interacting protein (TIPIN), and Claspin to damaged sites (Ciccia and Elledge, 2010; Jackson and Bartek, 2009). ATR phosphorylates some of these recruited proteins (Cimprich and Cortez, 2008; Flynn and Zou, 2011; Zeman and Cimprich, 2014). The accumulation and phosphorylation of these checkpoint regulators further stimulates the catalytic activity of ATR (Ciccia and Elledge, 2010; Cimprich and Cortez, 2008; Flynn and Zou, 2011; Jackson and Bartek, 2009; Zeman and Cimprich, 2014). For the efficient phosphorylation of Chk1 by ATR, Chk1 needs to form a complex with Claspin (Chini and Chen, 2004; Kumagai and Dunphy, 2000; Kumagai et al., 2004). Based on the localization of these proteins, ATR-induced Chk1 phosphorylation likely occurs at the sites of DNA damage on chromatin (Fig. 2) (Kasahara et al., 2010; Smits et al., 2006; Zhang et al., 2005).

The activated ATR phosphorylates Chk1 at Ser317 and Ser345 in its C-terminal regulatory domain (Fig. 2 and Table I) (Zhao and Piwnica-Worms, 2001). Chk1 phosphorylation at these sites (especially at Ser345) is critical for DNA damage checkpoint activation, replication control, and cell viability (Capasso et al., 2002; Niida et al., 2007; Wilsker et al., 2008). Functionally, ATR-induced phosphorylation elevates Chk1 catalytic activity (Fig. 2 and Table I) (Katsuragi and Sagata, 2004; Walker et al., 2009; Zhao and Piwnica-Worms, 2001): Ser345 is a more critical phosphor- 


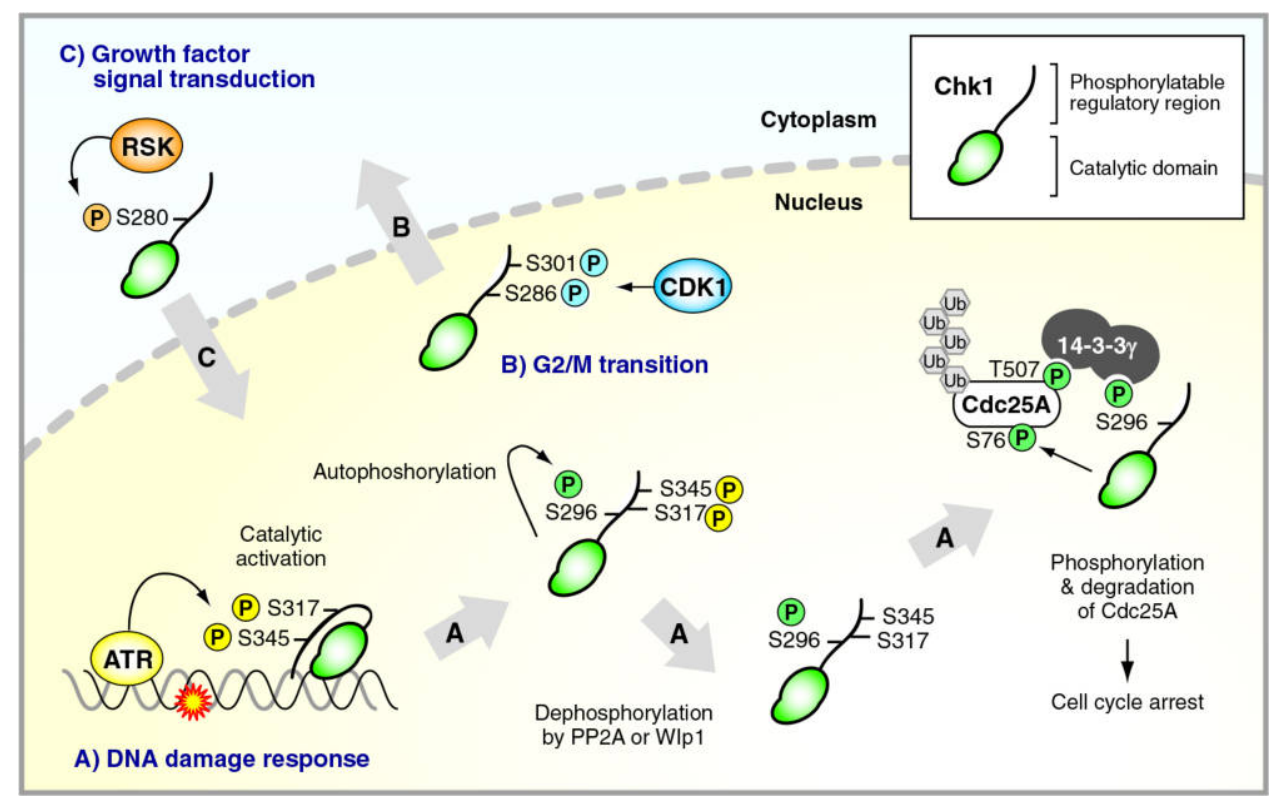

Fig. 2. Functional change of Chk1 by phosphorylation. A schematic representation of functional change by Chk1 phosphorylations during DNA damage response (DDR; A), at the G2/M transition (B), or in response to growth factor stimulation (C).

Table I. Functional CHANGE By PHOSPHORYLATION AT ITS C-TERMinAL REgUlatory DOMAIN

\begin{tabular}{|c|c|c|c|c|}
\hline Site & Stimulus & Kinase & Interactor & Effect on Chk1 function \\
\hline \multirow[t]{2}{*}{ Ser-280 } & Growth factor & p90 RSK & & Transport from cytoplasm to nucleus \\
\hline & UV irradiation & p90 RSK & & Acceleration of activation processes \\
\hline Ser-286 \& Ser-301 & $\mathrm{G} 2 / \mathrm{M}$ transition & CDK1 & & Transport from nucleus to cytopasm \\
\hline \multirow[t]{2}{*}{ Ser-296 } & DNA damage response (DDR) & Chk1 & $14-3-3 \gamma$ & 1) Interaction with $\mathrm{Cdc} 25 \mathrm{~A}$ via $14-3-3 \gamma$ \\
\hline & & & & 2) Release from DNA damage sites to entire nucleus \\
\hline Ser-317 \& Ser-345 & DDR & ATR & & Catalytic activation \\
\hline Ser-345 & DDR & ATR & $14-3-3 \beta / \zeta$ & Nuclear retention \\
\hline Ser-345 & DDR & ATR & & Polyubiquitylation \& degradation \\
\hline
\end{tabular}

ylation site for catalytic activation (Walker et al., 2009). The N-terminal catalytic domain of Chk1 adopts an open kinase conformation (Chen et al., 2000) and the deletion of C-terminal domain increases Chk1 catalytic activity (Chen et al., 2000; Katsuragi and Sagata, 2004). In fission yeast, the C-terminal domain contains a pseudo-substrate motif that facilitates the intra-molecular interaction (Biggins et al., 2008). These observations suggest a model in which the phosphorylation at two residues relieves an auto-inhibitory effect by the C-terminal regulatory domain (Biggins et al., 2008; Chen et al., 2000; Katsuragi and Sagata, 2004; Walker et al., 2009; Zhang et al., 2009). However, the pseudo-substrate motif does not appear to be conserved in Chk1 from other species. In addition, the deletion of the Cterminus abrogates Chk1 function in fission yeast (Caparelli and O'Connell, 2013; Kosoy and O'Connell, 2008), suggesting that the regulatory domain may play diverse roles in Chk1 activity. Therefore, much is still unknown about molecular mechanism by which Chk1 is structurally activated by phosphorylation.

Chk1-Ser345 phosphorylation regulates Chk1 function in addition to the catalytic activation. This phosphorylation creates a docking site for 14-3-3 $\beta$ or $\zeta$ (Table I) (Jiang et al., 2003). Since putative nuclear export signal (NES) sequence is located near Ser345 on Chk1 (Jiang et al., 2003; Wang et al., 2012), 14-3-3 $\beta$ or $\zeta$ competes with Crm-1 (a protein required for nuclear export; also called exportin 1) to the binding to Chk1 (Jiang et al., 2003), resulting in nuclear retention of Chk1 during DNA damage response (DDR; Table I) (Sanchez et al., 1997). Since nuclear Chk1 activity is critical to establish a checkpoint (Matsuyama et al., 2011; Reinhardt et al., 2010), the checkpoint activation processes are accelerated by nuclear accumulation of Chk1, together with its catalytic activation.

At later stage of DDR, Chk1 binds E3 ligases (such as $\mathrm{SCF}^{\mathrm{Fbx6}}$ in the cytoplasm and $\mathrm{Cul}_{4} \mathrm{~A}^{\mathrm{CDT} 2}$ in the nucleus), 
which requires preceding Chk1-Ser345 phosphorylation (Table I) (Huh and Piwnica-Worms, 2013; Leung-Pineda et al., 2009; Zhang et al., 2009, 2005). The interaction with E3 ligases induces proteasome-dependent Chk1 degradation (Table I), resulting in checkpoint termination and cellcycle resumption (Huh and Piwnica-Worms, 2013; LeungPineda et al., 2009; Zhang et al., 2009; Zhang et al., 2005). However, there is $\sim 4-\mathrm{hr}$ difference between Chk1 phosphorylation and the onset of degradation (Zhang et al., 2005). Thus, much is still unknown about a signaling pathway from Chk1 phosphorylation to degradation during DDR.

\section{Chk1 Autophosphorylation (Especially at Ser296)}

During DDR, Chk1 is autophosphorylated at several sites including Ser296 just after Chk1 phosphorylation at Ser317 and Ser345 by ATR (which implies Chk1 catalytic activation; Fig. 2) (Clarke and Clarke, 2005; Kasahara et al., 2010). After Chk1 autophosphorylation, ATR sites are rapidly dephosphorylated by phosphatases such as protein phosphatase 2A (PP2A) (Kasahara et al., 2010; LeungPineda et al., 2006) or PPM1D (also called Wip1 or PP2C 8 ; Fig. 2) (Lu et al., 2005). Ser296-phosphorylated Chk1 is diffusely detected in the entire nucleus (nucleoplasm; soluble nuclear fraction), whereas Ser345-phosphorylated Chk1 is predominantly observed at DNA damage foci (Kasahara et al., 2010). These observations lead to a model in which this phosphorylation shift promotes the release of Chk1 from DNA damage foci on the chromatin (Fig. 2 and Table I). Since ATR-mediated phosphorylation induces Chk1 autophosphorylation (the most likely direct trigger to spread Chk1 signals over nucleus) (Kasahara et al., 2010), this model fits with the observation that Ser345 phosphorylation triggers Chk1 release from the chromatin (Shimada et al., 2008; Smits et al., 2006; Zhang et al., 2005). Since important downstream effectors such as Cdc25A are distributed diffusely in the nucleus (Bekker-Jensen et al., 2006), the redistribution to the entire nucleus is essential for Chk1 to deliver checkpoint signals (Smits et al., 2006).

Among Chk1 autophosphorylation sites, Ser296 is the most critical phosphorylation site for the checkpoint function (Kasahara et al., 2010). Ser296 phosphorylation creates a docking site for 14-3-3 $\gamma$ (Fig. 2 and Table I) (Kasahara et al., 2010). Since Chk1 also generates 14-3-3binding sites on Cdc25A (Chen et al., 2003), dimerization of 14-3-3 proteins (Mohammad and Yaffe, 2009) facilitates the formation of ternary complex among Chk1, Cdc25A, and 14-3-3 $\gamma$ (Fig. 2) (Kasahara et al., 2010). This complex formation is essential for Chk1 to phosphorylate Ser76 on Cdc25A (Fig. 2), whereas it is dispensable for Cdc25 phosphorylation at Thr507 (a phosphorylation site required for 14-3-3 binding) (Chen et al., 2003) by Chk1 (Kasahara et al., 2010). Ser76 is known as a rate-limiting phosphorylation site for Cdc25A degradation (Boutros et al., 2007; Busino et al., 2004; Jin et al., 2003; Neely and PiwnicaWorms, 2003). Ser76 phosphorylation triggers additional Cdc25A phosphorylations by NEK11 (Melixetian et al., 2009) and casein kinase 1 (CK1) (Honaker and PiwnicaWorms, 2010), which generate a $\beta$-TrCP (E3 ligase) recognition motif (phosphodegron) on Cdc25A. This proteasome-dependent $\mathrm{Cdc} 25 \mathrm{~A}$ degradation prevents premature activation of CDKs, resulting in cell-cycle arrest. Thus, Chk1-Ser296 autophosphorylation is one of critical steps for checkpoint signaling during DDR.

\section{Chk1 Phosphorylation by CDKs}

Chk1 also plays critical roles in normal (unperturbed) cellcycle progression. Essential functions of Chk1 during development are well documented by the early embryonic lethality of Chk1-knockout mice (Liu et al., 2000; Takai et al., 2000). It is conceivable that Chk1 monitors replication forks in S phase (Maya-Mendoza et al., 2007; Syljuasen et al., 2005; Takai et al., 2000). Chk1 activity is necessary to prevent late-origin firing and then irreversible replication fork collapse (Maya-Mendoza et al., 2007). At the G2 phase, Chk1 inhibits premature mitotic entry (Enomoto et al., 2009; Kramer et al., 2004; Matsuyama et al., 2011). Thus, Chk1 has an activity to negatively regulate cell-cycle progression even without exogenously introducing DNA damage. However, there is a debate as to whether or not ATR participates in Chk1 activity during normal (unperturbed) cell-cycle progression (Brown and Baltimore, 2000; de Klein et al., 2000; Shimada et al., 2008).

At the G2/M transition, Chk1 is phosphorylated at Ser286 and Ser301 by CDK1 (Shiromizu et al., 2006), a mitotic inducer kinase (Fig. 2 and Table I). This phosphorylation stimulates Chk1 transport from the nucleus to the cytoplasm in a Crm-1-dependent manner (Fig. 2 and Table I) (Enomoto et al., 2009; Matsuyama et al., 2011). This transport relieves Chk1 inhibitory activity against CDK1 in the nucleus, leading to mitotic progression (Table I) (Enomoto et al., 2009; Matsuyama et al., 2011). This nuclear model appears to conflict with reports that a small fraction of Chk1 localizes to the centrosome to block premature mitotic entry (Kramer et al., 2004; Tibelius et al., 2009). However, an anti-Chk1 antibody used for immunostaining in these studies (Kramer et al., 2004; Tibelius et al., 2009) clearly cross-reacts with a centrosomal protein other than Chk1 (Matsuyama et al., 2011). In addition, forced immobilization of Chk1 to the centrosome has little impact on the timing of mitotic entry, whereas Chk1-NLS (a mutant localized predominantly in the nucleus) clearly delays mitotic entry in the same experimental condition (Matsuyama et al., 2011). Therefore, nuclear but not centrosomal Chk1 prevents CDK1 from unscheduled activa- 
tion before mitosis. CDK1 relieves the inhibitory effect though nuclear exclusion of Chk1 by phosphorylation. In other words, there is a positive feedback loop between CDK1 and Chk1 at the G2/M transition.

As described above, accumulating data support the view that Chk1 functions as a negative cell-cycle regulator mainly in the nucleus. However, CDK1 is first activated at the centrosome during the G2/M transition (Jackman et al., 2003), raising the question as to which factor(s) transduce checkpoint signals to the cytoplasm and the centrosome. Several groups pointed out a novel checkpoint pathway mediated by $\mathrm{p} 38$ and MK2 that operates parallel to Chk1 and is activated downstream of ATM and ATR (Bulavin et al., 2001; Manke et al., 2005; Raman et al., 2007; Reinhardt et al., 2007; Reinhardt and Yaffe, 2009). Chk1 controls nuclear events but p38-MK2 pathway regulates cytoplasmic events in the checkpoint responses (Reinhardt et al., 2010). Since p38 phosphorylates and then inhibits Cdc25B (a centrosomal subtype of Cdc25) (Bulavin et al., 2001), the p38-MK2 pathway may be one of likely candidates to transmit checkpoint signals to the cytoplasm and the centrosome.

Ser286 and Ser301 are also phosphorylated during DDR (Ikegami et al., 2008). CDK2 or CDK1 is responsible for Chk1 phosphorylation at Ser286 and Ser301 during DDR (Ikegami et al., 2008; Xu et al., 2012, 2011). Unlike in mitosis, CDK-induced phosphorylation occurs simultaneously with the phosphorylation at Ser317 and Ser345 by ATR during DDR (Ikegami et al., 2008). The co-existence of Ser345 phosphorylation likely turns off Crm-1-mediated nuclear export by CDK-induced phosphorylation, because Ser345 phosphorylation promotes Chk1 binding to 14-3-3 $\beta$ or $\zeta$, which competes with Crm-1 (Jiang et al., 2003). Although CDK-mediated Chk1 phosphorylation was reported to reinforce checkpoint signaling (Xu et al., 2012, 2011), less is known about the significance of this phosphorylation during DDR than at the G2/M transition.

\section{Chk1 Phosphorylation at Ser280}

In quiescent cells (G0 phase cells), Chk1 is localized diffusely both in the nucleus and the cytoplasm ( $\mathrm{Li}$ et al., 2012). At the G0/G1 transition, Chk1 is phosphorylated predominantly at Ser280 by p90 RSK downstream of the Ras-MAPK cascade (Fig. 2 and Table I) (Li et al., 2012). Ser280 phosphorylation promotes Chk1 translocation from the cytoplasm to the nucleus (Fig. 2 and Table I) (Li et al., 2012). Since Chk1 is activated in the nucleus during DDR (Jiang et al., 2003; Sanchez et al., 1997), such nuclear accumulation is likely to be of great use to maintain genomic integrity during cell-cycle progression. In support of this hypothesis, Ser280 phosphorylation accelerates Chk1 activation processes after UV irradiation (Table I) ( $\mathrm{Li}$ et al., 2012).
In response to DNA damage during the G2 phase, Akt/PKB was also reported to induce Chk1 phosphorylation at Ser280 (King et al., 2004; Shtivelman et al., 2002) and to reduce nuclear localization of Chk1 (Puc et al., 2005). However, the in vitro analysis reveals that $\mathrm{Akt} / \mathrm{PKB}$ phosphorylates Chk1 at several sites, among which Ser280 is only a minor phosphorylation site ( $\mathrm{Li}$ et al., 2012). In addition, Chk1-Ser280 mutants behaved like Chk1 wild type in the G2/M checkpoint (Tonic et al., 2010; Xu et al., 2010). Although Akt/PKB negatively regulates the G2/M checkpoint (Henry et al., 2001; Nimbalkar and Quelle, 2008; Shtivelman et al., 2002; Xu et al., 2010), there is a debate as to whether $\mathrm{G} 2 / \mathrm{M}$ checkpoint is negatively regulated by Chk1-Ser 280 phosphorylation.

\section{Conclusion}

Remarkable progress has been made in understanding Chk1 regulation. Chk1 is phosphorylated by a variety of protein kinases. The resulting phosphorylations change catalytic activity, binding partners and/or localization of Chk1. The functional change(s) by phosphorylation(s) enable Chk1 to control not only DDR but also normal cell-cycle progression. The development of Chk1-targeted molecular therapies calls for a more advanced molecular understanding of Chk1 especially in normal cell-cycle progression in the absence of exogenous DNA damages.

Acknowledgments. This work was supported in part by Grants-in-Aid for Scientific Research from the Japan Society for the Promotion of Science and from the Ministry of Education, Culture, Sports, Science and Technology of Japan; and by the Takeda Science Foundation. We thank Dr. T. Magin (University Leipzig, Germany) for critical comments. We sincerely apologize to all our colleagues whose work we were unable to cite due to space limitations. H.G. and M.I. has received research funding form the Takeda Science Foundation, which was established in 1963 with an endowment from Takeda Pharmaceutical Company Ltd.

\section{References}

Antoni, L., Sodha, N., Collins, I., and Garrett, M.D. 2007. CHK2 kinase: cancer susceptibility and cancer therapy - two sides of the same coin? Nat. Rev. Cancer, 7: 925-936.

Appella, E. and Anderson, C.W. 2001. Post-translational modifications and activation of p53 by genotoxic stresses. Eur. J. Biochem., 268: 2764-2772.

Bekker-Jensen, S., Lukas, C., Kitagawa, R., Melander, F., Kastan, M.B., Bartek, J., and Lukas, J. 2006. Spatial organization of the mammalian genome surveillance machinery in response to DNA strand breaks. $J$. Cell Biol., 173: 195-206.

Biggins, S., Palermo, C., Hope, J.C., Freyer, G.A., Rao, H., and Walworth, N.C. 2008. Importance of a C-Terminal Conserved Region of Chk1 for Checkpoint Function. PLoS ONE, 3: e1427.

Boutros, R., Lobjois, V., and Ducommun, B. 2007. CDC25 phosphatases in cancer cells: key players? Good targets? Nat. Rev. Cancer, 7: 495-507.

Brown, E.J. and Baltimore, D. 2000. ATR disruption leads to chromosomal fragmentation and early embryonic lethality. Genes Dev., 14: 397402. 
Bulavin, D.V., Higashimoto, Y., Popoff, I.J., Gaarde, W.A., Basrur, V., Potapova, O., Appella, E., and Fornace, A.J., Jr. 2001. Initiation of a G2/M checkpoint after ultraviolet radiation requires p38 kinase. Nature, 411: 102-107.

Busino, L., Chiesa, M., Draetta, G.F., and Donzelli, M. 2004. Cdc25A phosphatase: combinatorial phosphorylation, ubiquitylation and proteolysis. Oncogene, 23: 2050-2056.

Caparelli, M.L. and O'Connell, M.J. 2013. Regulatory motifs in Chk1. Cell Cycle, 12: 916-922.

Capasso, H., Palermo, C., Wan, S., Rao, H., John, U.P., O'Connell, M.J., and Walworth, N.C. 2002. Phosphorylation activates Chk1 and is required for checkpoint-mediated cell cycle arrest. J. Cell Sci., 115(Pt 23): 4555-4564.

Carrassa, L. and Damia, G. 2011. Unleashing Chk1 in cancer therapy. Cell Cycle, 10: 2121-2128.

Chen, M.S., Ryan, C.E., and Piwnica-Worms, H. 2003. Chk1 Kinase Negatively Regulates Mitotic Function of Cdc25A Phosphatase through 14-3-3 Binding. Mol. Cell. Biol., 23: 7488-7497.

Chen, P., Luo, C., Deng, Y., Ryan, K., Register, J., Margosiak, S., Tempczyk-Russell, A., Nguyen, B., Myers, P., Lundgren, K., and others. 2000. The 1.7 A crystal structure of human cell cycle checkpoint kinase Chk1: implications for Chk1 regulation. Cell, 100: 681-692.

Chini, C.C. and Chen, J. 2004. Claspin, a regulator of Chk1 in DNA replication stress pathway. DNA Repair (Amst), 3: 1033-1037.

Ciccia, A. and Elledge, S.J. 2010. The DNA damage response: making it safe to play with knives. Mol. Cell, 40: 179-204.

Cimprich, K.A. and Cortez, D. 2008. ATR: an essential regulator of genome integrity. Nat. Rev. Mol. Cell Biol., 9: 616-627.

Clarke, C.A. and Clarke, P.R. 2005. DNA-dependent phosphorylation of Chk1 and Claspin in a human cell-free system. Biochem. J., 388( $\mathrm{Pt} 2)$ : 705-712.

Cremona, C.A. and Behrens, A. 2014. ATM signalling and cancer. Oncogene, 33: 3351-3360.

Dai, Y. and Grant, S. 2010. New insights into checkpoint kinase 1 in the DNA damage response signaling network. Clin. Cancer Res., 16: 376383.

de Klein, A., Muijtjens, M., van Os, R., Verhoeven, Y., Smit, B., Carr, A.M., Lehmann, A.R., and Hoeijmakers, J.H. 2000. Targeted disruption of the cell-cycle checkpoint gene ATR leads to early embryonic lethality in mice. Curr. Biol., 10: 479-482.

Enomoto, M., Goto, H., Tomono, Y., Kasahara, K., Tsujimura, K., Kiyono, T., and Inagaki, M. 2009. Novel positive feedback loop between Cdk1 and Chk1 in the nucleus during G2/M transition. J. Biol. Chem., 284: 34223-34230.

Flynn, R.L. and Zou, L. 2011. ATR: a master conductor of cellular responses to DNA replication stress. Trends Biochem. Sci., 36: 133140 .

Goto, H., Izawa, I., Li, P., and Inagaki, M. 2012. Novel regulation of checkpoint kinase 1: Is checkpoint kinase 1 a good candidate for anticancer therapy? Cancer Sci., 103: 1195-1200.

Henry, M.K., Lynch, J.T., Eapen, A.K., and Quelle, F.W. 2001. DNA damage-induced cell-cycle arrest of hematopoietic cells is overridden by activation of the PI-3 kinase/Akt signaling pathway. Blood, 98: 834841.

Honaker, Y. and Piwnica-Worms, H. 2010. Casein kinase 1 functions as both penultimate and ultimate kinase in regulating Cdc25A destruction. Oncogene, 29: 3324-3334.

Huh, J. and Piwnica-Worms, H. 2013. CRL4(CDT2) targets CHK1 for PCNA-independent destruction. Mol. Cell. Biol., 33: 213-226.

Ikegami, Y., Goto, H., Kiyono, T., Enomoto, M., Kasahara, K., Tomono, Y., Tozawa, K., Morita, A., Kohri, K., and Inagaki, M. 2008. Chk1 phosphorylation at Ser286 and Ser301 occurs with both stalled DNA replication and damage checkpoint stimulation. Biochem. Biophys. Res.
Commun., 377: 1227-1231.

Jackman, M., Lindon, C., Nigg, E.A., and Pines, J. 2003. Active cyclin B1-Cdk1 first appears on centrosomes in prophase. Nat. Cell Biol., 5: $143-148$.

Jackson, S.P. and Bartek, J. 2009. The DNA-damage response in human biology and disease. Nature, 461: 1071-1078.

Jiang, K., Pereira, E., Maxfield, M., Russell, B., Goudelock, D.M., and Sanchez, Y. 2003. Regulation of Chk1 includes chromatin association and 14-3-3 binding following phosphorylation on Ser-345. J. Biol. Chem., 278: 25207-25217.

Jin, J., Shirogane, T., Xu, L., Nalepa, G., Qin, J., Elledge, S.J., and Harper, J.W. 2003. SCFbeta-TRCP links Chk1 signaling to degradation of the Cdc25A protein phosphatase. Genes Dev., 17: 3062-3074.

Kandoth, C., McLellan, M.D., Vandin, F., Ye, K., Niu, B., Lu, C., Xie, M., Zhang, Q., McMichael, J.F., Wyczalkowski, M.A., and others. 2013. Mutational landscape and significance across 12 major cancer types. Nature, 502: 333-339.

Kasahara, K., Goto, H., Enomoto, M., Tomono, Y., Kiyono, T., and Inagaki, M. 2010. 14-3-3gamma mediates Cdc25A proteolysis to block premature mitotic entry after DNA damage. EMBO J., 29: 2802-2812.

Katsuragi, Y. and Sagata, N. 2004. Regulation of Chk1 kinase by autoinhibition and ATR-mediated phosphorylation. Mol. Biol. Cell, 15: 16801689.

King, F.W., Skeen, J., Hay, N., and Shtivelman, E. 2004. Inhibition of Chk1 by activated PKB/Akt. Cell Cycle, 3: 634-637.

Kosoy, A. and O'Connell, M.J. 2008. Regulation of Chk1 by its Cterminal domain. Mol. Biol. Cell, 19: 4546-4553.

Kramer, A., Mailand, N., Lukas, C., Syljuasen, R.G., Wilkinson, C.J., Nigg, E.A., Bartek, J., and Lukas, J. 2004. Centrosome-associated Chk1 prevents premature activation of cyclin-B-Cdk1 kinase. Nat. Cell Biol., 6: 884-891.

Kumagai, A. and Dunphy, W.G. 2000. Claspin, a novel protein required for the activation of Chk1 during a DNA replication checkpoint response in Xenopus egg extracts. Mol. Cell, 6: 839-849.

Kumagai, A., Kim, S.M., and Dunphy, W.G. 2004. Claspin and the activated form of ATR-ATRIP collaborate in the activation of Chk1. J. Biol. Chem., 279: 49599-49608.

Lawrence, M.S., Stojanov, P., Mermel, C.H., Robinson, J.T., Garraway, L.A., Golub, T.R., Meyerson, M., Gabriel, S.B., Lander, E.S., and Getz, G. 2014. Discovery and saturation analysis of cancer genes across 21 tumour types. Nature, 505: 495-501.

Leung-Pineda, V., Ryan, C.E., and Piwnica-Worms, H. 2006. Phosphorylation of Chk1 by ATR is antagonized by a Chk1-regulated protein phosphatase 2A circuit. Mol. Cell. Biol., 26: 7529-7538.

Leung-Pineda, V., Huh, J., and Piwnica-Worms, H. 2009. DDB1 targets Chk1 to the Cul4 E3 ligase complex in normal cycling cells and in cells experiencing replication stress. Cancer Res., 69: 2630-2637.

Li, P., Goto, H., Kasahara, K., Matsuyama, M., Wang, Z., Yatabe, Y., Kiyono, T., and Inagaki, M. 2012. P90 RSK arranges Chk1 in the nucleus for monitoring of genomic integrity during cell proliferation. Mol. Biol. Cell, 23: 1582-1592.

Liu, Q., Guntuku, S., Cui, X.S., Matsuoka, S., Cortez, D., Tamai, K., Luo, G., Carattini-Rivera, S., DeMayo, F., Bradley, A., and others. 2000. Chk1 is an essential kinase that is regulated by Atr and required for the G(2)/M DNA damage checkpoint. Genes Dev., 14: 1448-1459.

Lu, X., Nannenga, B., and Donehower, L.A. 2005. PPM1D dephosphorylates Chk1 and p53 and abrogates cell cycle checkpoints. Genes Dev., 19: $1162-1174$

Lukas, C., Falck, J., Bartkova, J., Bartek, J., and Lukas, J. 2003. Distinct spatiotemporal dynamics of mammalian checkpoint regulators induced by DNA damage. Nat. Cell Biol., 5: 255-260.

Ma, C.X., Janetka, J.W., and Piwnica-Worms, H. 2011. Death by releasing the breaks: CHK1 inhibitors as cancer therapeutics. Trends Mol. 
Med., 17: 88-96.

Manke, I.A., Nguyen, A., Lim, D., Stewart, M.Q., Elia, A.E., and Yaffe, M.B. 2005. MAPKAP kinase-2 is a cell cycle checkpoint kinase that regulates the $\mathrm{G} 2 / \mathrm{M}$ transition and $\mathrm{S}$ phase progression in response to UV irradiation. Mol. Cell, 17: 37-48.

Matsuyama, M., Goto, H., Kasahara, K., Kawakami, Y., Nakanishi, M., Kiyono, T., Goshima, N., and Inagaki, M. 2011. Nuclear Chk1 prevents premature mitotic entry. J. Cell Sci., 124(Pt 13): 2113-2119.

Maugeri-Sacca, M., Bartucci, M., and De Maria, R. 2013. Checkpoint kinase 1 inhibitors for potentiating systemic anticancer therapy. Cancer Treat. Rev., 39: 525-533.

Maya-Mendoza, A., Petermann, E., Gillespie, D.A., Caldecott, K.W., and Jackson, D.A. 2007. Chk1 regulates the density of active replication origins during the vertebrate $\mathrm{S}$ phase. EMBO J., 26: 2719-2731.

McGowan, C.H. 2002. Checking in on Cds1 (Chk2): A checkpoint kinase and tumor suppressor. Bioessays, 24: 502-511.

Melixetian, M., Klein, D.K., Sorensen, C.S., and Helin, K. 2009. NEK11 regulates $\mathrm{CDC} 25 \mathrm{~A}$ degradation and the IR-induced G2/M checkpoint. Nat. Cell Biol., 11: 1247-1253.

Mohammad, D.H. and Yaffe, M.B. 2009. 14-3-3 proteins, FHA domains and BRCT domains in the DNA damage response. DNA Repair (Amst), 8: $1009-1017$.

Neely, K.E. and Piwnica-Worms, H. 2003. Cdc25A regulation: to destroy or not to destroy--is that the only question? Cell Cycle, 2: 455-457.

Niida, H., Katsuno, Y., Banerjee, B., Hande, M.P., and Nakanishi, M. 2007. Specific role of Chk1 phosphorylations in cell survival and checkpoint activation. Mol. Cell. Biol., 27: 2572-2581.

Nimbalkar, D. and Quelle, F.W. 2008. Phosphoinositide 3-kinase signaling overrides a G2 phase arrest checkpoint and promotes aberrant cell cycling and death of hematopoietic cells after DNA damage. Cell Cycle, 7: $2877-2885$.

Polager, S. and Ginsberg, D. 2009. p53 and E2f: partners in life and death. Nat. Rev. Cancer, 9: 738-748.

Puc, J., Keniry, M., Li, H.S., Pandita, T.K., Choudhury, A.D., Memeo, L., Mansukhani, M., Murty, V.V., Gaciong, Z., Meek, S.E., and others. 2005. Lack of PTEN sequesters CHK1 and initiates genetic instability. Cancer Cell, 7: 193-204.

Raman, M., Earnest, S., Zhang, K., Zhao, Y., and Cobb, M.H. 2007. TAO kinases mediate activation of $\mathrm{p} 38$ in response to DNA damage. $E M B O$ J., 26: 2005-2014.

Reinhardt, H.C., Aslanian, A.S., Lees, J.A., and Yaffe, M.B. 2007. p53Deficient Cells Rely on ATM- and ATR-Mediated Checkpoint Signaling through the p38MAPK/MK2 Pathway for Survival after DNA Damage. Cancer Cell, 11: 175-189.

Reinhardt, H.C. and Yaffe, M.B. 2009. Kinases that control the cell cycle in response to DNA damage: Chk1, Chk2, and MK2. Curr. Opin. Cell Biol., 21: 245-255.

Reinhardt, H.C., Hasskamp, P., Schmedding, I., Morandell, S., van Vugt, M.A., Wang, X., Linding, R., Ong, S.E., Weaver, D., Carr, S.A., and others. 2010. DNA damage activates a spatially distinct late cytoplasmic cell-cycle checkpoint network controlled by MK2-mediated RNA stabilization. Mol. Cell, 40: 34-49.

Rhind, N. and Russell, P. 2000. Chk1 and Cds1: linchpins of the DNA damage and replication checkpoint pathways. J. Cell Sci., 113(Pt 22): 3889-3896.

Riley, T., Sontag, E., Chen, P., and Levine, A. 2008. Transcriptional control of human p53-regulated genes. Nat Rev Mol. Cell Biol., 9: 402-412.

Sanchez, Y., Wong, C., Thoma, R.S., Richman, R., Wu, Z., PiwnicaWorms, H., and Elledge, S.J. 1997. Conservation of the Chk1 checkpoint pathway in mammals: linkage of DNA damage to Cdk regulation through Cdc25. Science, 277: 1497-1501.

Shiloh, Y. and Ziv, Y. 2013. The ATM protein kinase: regulating the cellular response to genotoxic stress, and more. Nat. Rev. Mol. Cell Biol., 14:
197-210.

Shimada, M., Niida, H., Zineldeen, D.H., Tagami, H., Tanaka, M., Saito, H., and Nakanishi, M. 2008. Chk1 is a histone H3 threonine 11 kinase that regulates DNA damage-induced transcriptional repression. Cell, 132: 221-232.

Shiromizu, T., Goto, H., Tomono, Y., Bartek, J., Totsukawa, G., Inoko, A., Nakanishi, M., Matsumura, F., and Inagaki, M. 2006. Regulation of mitotic function of Chk1 through phosphorylation at novel sites by cyclin-dependent kinase 1 (Cdk1). Genes Cells, 11: 477-485.

Shtivelman, E., Sussman, J., and Stokoe, D. 2002. A role for PI 3-kinase and PKB activity in the G2/M phase of the cell cycle. Curr. Biol., 12: 919-924.

Smits, V.A., Reaper, P.M., and Jackson, S.P. 2006. Rapid PIKK-dependent release of Chk1 from chromatin promotes the DNA-damage checkpoint response. Curr. Biol., 16: 150-159.

Syljuasen, R.G., Sorensen, C.S., Hansen, L.T., Fugger, K., Lundin, C., Johansson, F., Helleday, T., Sehested, M., Lukas, J., and Bartek, J. 2005. Inhibition of human Chk1 causes increased initiation of DNA replication, phosphorylation of ATR targets, and DNA breakage. Mol. Cell. Biol., 25: 3553-3562.

Takai, H., Tominaga, K., Motoyama, N., Minamishima, Y.A., Nagahama, H., Tsukiyama, T., Ikeda, K., Nakayama, K., Nakanishi, M., and Nakayama, K. 2000. Aberrant cell cycle checkpoint function and early embryonic death in Chk1(-/-) mice. Genes Dev., 14: 1439-1447.

Thompson, R. and Eastman, A. 2013. The cancer therapeutic potential of Chk1 inhibitors: how mechanistic studies impact on clinical trial design. Br. J. Clin. Pharmacol., 76: 358-369.

Tibelius, A., Marhold, J., Zentgraf, H., Heilig, C.E., Neitzel, H., Ducommun, B., Rauch, A., Ho, A.D., Bartek, J., and Kramer, A. 2009. Microcephalin and pericentrin regulate mitotic entry via centrosomeassociated Chk1. J. Cell Biol., 185: 1149-1157.

Tonic, I., Yu, W.N., Park, Y., Chen, C.C., and Hay, N. 2010. Akt activation emulates Chk1 inhibition and $\mathrm{Bcl} 2$ overexpression and abrogates G2 cell cycle checkpoint by inhibiting BRCA1 foci. J. Biol. Chem., 285: 23790-23798.

Vandin, F., Upfal, E., and Raphael, B.J. 2012. De novo discovery of mutated driver pathways in cancer. Genome Res., 22: 375-385.

Wade, M., Li, Y.C., and Wahl, G.M. 2013. MDM2, MDMX and p53 in oncogenesis and cancer therapy. Nat. Rev. Cancer, 13: 83-96.

Walker, M., Black, E.J., Oehler, V., Gillespie, D.A., and Scott, M.T. 2009. Chk1 C-terminal regulatory phosphorylation mediates checkpoint activation by de-repression of Chk1 catalytic activity. Oncogene, 28: 2314 2323 .

Wang, J., Han, X., Feng, X., Wang, Z., and Zhang, Y. 2012. Coupling cellular localization and function of checkpoint kinase $1(\mathrm{Chk} 1)$ in checkpoints and cell viability. J. Biol. Chem., 287: 25501-25509.

Wilsker, D., Petermann, E., Helleday, T., and Bunz, F. 2008. Essential function of Chk1 can be uncoupled from DNA damage checkpoint and replication control. Proc. Natl. Acad. Sci. USA, 105: 20752-20757.

Xu, N., Hegarat, N., Black, E.J., Scott, M.T., Hochegger, H., and Gillespie, D.A. 2010. Akt/PKB suppresses DNA damage processing and checkpoint activation in late G2. J. Cell Biol., 190: 297-305.

Xu, N., Libertini, S., Zhang, Y., and Gillespie, D.A. 2011. Cdk phosphorylation of Chk1 regulates efficient Chk1 activation and multiple checkpoint proficiency. Biochem. Biophys. Res. Commun., 413: 465-470.

Xu, N., Libertini, S., Black, E.J., Lao, Y., Hegarat, N., Walker, M., and Gillespie, D.A. 2012. Cdk-mediated phosphorylation of Chk1 is required for efficient activation and full checkpoint proficiency in response to DNA damage. Oncogene, 31: 1086-1094.

Zeman, M.K. and Cimprich, K.A. 2014. Causes and consequences of replication stress. Nat. Cell Biol., 16: 2-9.

Zhang, Y. and Hunter, T. 2014. Roles of Chk1 in cell biology and cancer therapy. Int. J. Cancer, 134: 1013-1023. 
Zhang, Y.W., Otterness, D.M., Chiang, G.G., Xie, W., Liu, Y.C., Mercurio, F., and Abraham, R.T. 2005. Genotoxic stress targets human Chk1 for degradation by the ubiquitin-proteasome pathway. Mol. Cell, 19: 607618.

Zhang, Y.W., Brognard, J., Coughlin, C., You, Z., Dolled-Filhart, M., Aslanian, A., Manning, G., Abraham, R.T., and Hunter, T. 2009. The F box protein Fbx6 regulates Chk1 stability and cellular sensitivity to rep- lication stress. Mol. Cell, 35: 442-453.

Zhao, H. and Piwnica-Worms, H. 2001. A TR-mediated checkpoint pathways regulate phosphorylation and activation of human Chk1. Mol. Cell. Biol., 21: 4129-4139.

(Received for publication, November 8, 2014, accepted, December 18, 2014 and published online, December 25, 2014) 